\title{
Structure of $\mathrm{PtRu} / \mathrm{Ru}(0001)$ and $\mathrm{AgPd} / \mathrm{Pd}(111)$ surface alloys: $\mathrm{A}$ kinetic Monte Carlo study
}

\author{
David Mahlberg* and Sung Sakong ${ }^{\dagger}$ \\ Institute of Theoretical Chemistry, Ulm University, 89069 Ulm, Germany \\ Axel Groß \\ Institute of Theoretical Chemistry, Ulm University, 89069 Ulm, Germany and \\ Helmholtz Institute Ulm (HIU), Electrochemical Energy Storage, 89069 Ulm, Germany
}

\begin{abstract}
Bimetallic surfaces allow tailoring their catalytic activity by modifying their composition and/or structure. However, under operating conditions, catalytically active bimetallic structures are often not stable and change their morphology which might reduce their functionality. Still, catalytically active structures do not necessarily need to be thermodynamically stable and might also be kinetically stabilized. Here we report kinetic Monte Carlo simulations based on density functional theory calculation to address the meta-stability of surface alloy systems. As structural changes can typically only occur via vacancy diffusion in the surface, we first determine the vacancy diffusion barrier as a function of their bimetallic environment. By determining the temporal evolution of the bimetallic surface alloys as a function of temperature, we analyze the factors underlying the stability and structure of the bimetallic surface alloys.
\end{abstract}




\section{INTRODUCTION}

Nowadays, highly optimized catalysts are used to produce most chemical products in the industry. Due to the limited abundance of catalytically active materials, both the chemical industry and academic fields aim to understand and improve the catalysts for the efficient use of available resources ${ }^{1,2}$. One of the options is to introduce alloy materials instead of single metals for heterogeneous catalysts to improve activity and selectivity ${ }^{3,4}$. The facile blending of the alloy components allows to modify the electronic properties and subsequently optimize the performance of catalysts. Controlling additional parameters such as the structure and composition of the alloys offers significant possibilities towards a rational catalyst design by realizing, e.g., single atom alloys ${ }^{5-9}$, bimetallic surface alloys and alloy surfaces ${ }^{10-13}$, or high entropy alloy catalysts ${ }^{14,15}$. The tailored alloy materials might also substitute or reduce the use of rare and expensive metal elements in the catalysts while retaining the performance of the catalysts. One of the straightforward ways to tailor such catalysts is by coating a host material or nanoparticle with a catalytically active guest metal ${ }^{16-18}$.

Often, the catalysts are designed by a more reactive guest element and a more inert host element, e.g. $\mathrm{PtRu}^{19,20}, \mathrm{PtAu}^{21}, \mathrm{AgRh}^{22}$, and $\mathrm{PdCu}^{23}$. The performance of alloy catalysts can be estimated employing descriptors and scaling relations ${ }^{18,24}$, where the local reactivity can be identified by the adsorption energy of probe molecules ${ }^{6,25,26}$. The local reactivity can be characterized invoking ligand and ensemble effects, i.e., the electronic interaction and local configuration of the alloy components ${ }^{7,23,27}$. In addition to the electronic and geometric contributions, strain effects need to be considered when there is a large lattice mismatch between the host and guest elements ${ }^{28,29}$.

Atomistic modeling can help to identify catalytically active configurations. However, the most active configurations are not necessarily thermodynamically stable. A thermodynamically stable and active configuration guarantees the longevity of catalysts ${ }^{30}$, but active sites can be kinetically created and reduced to inactive ones after some operation period. Random bimetallic surface alloys can be used as a model catalysts to investigate the local configuration of thermodynamically unstable active sites and the time evolution of their populations under operating conditions. All possible geometric structures, including active sites, are created in a random alloy layer by annealing the bimetallic catalyst at high temperature. The generated configurations can be frozen by flash-cooling. Then, the thermodynamically un- 
stable local configurations will become kinetically stabilized at operating temperature lower than the annealing temperature. Still, active sites within unstable configurations might lose their activity over time ${ }^{31-34}$.

State-of-the-art density functional theory (DFT) based calculations are still too demanding, even on modern supercomputers, to sample a sufficient number of atomic configurations statistically ${ }^{35,36}$. Nevertheless, there exist feasible numerical methods to study the stability of the surface alloys on the DFT level of accuracy, namely the lattice gas Hamiltonian (LGH) method ${ }^{37,38}$. As demonstrated by Behm et al., a model Hamiltonian parametrized by first-principles calculations through cluster expansion (CE) techniques can provide good estimates for the formation energies of alloys ${ }^{39-41}$. However, the time evolution of the alloy configuration at any operating temperature requires an explicit consideration of surface kinetics. It is widely accepted that the kinetic Monte-Carlo (kMC) method can simulate atomistic processes adequately when a complete table of the reactions is known. Within this approach, the accuracy of the reaction barriers determines the quality of the simulations. Typically, activation barriers calculated by DFT methods entering kMC simulations through transtion state theory ${ }^{42}$ allow to describe the properties of metals and ordered metal alloys satisfactorily ${ }^{43-46}$.

Numerically, $\mathrm{kMC}$ is a coarse-grained, lattice-based atomistic simulation method that calculates the time-dependent fluctuation of discrete states ${ }^{44,47-49}$. Events and timesteps follow a Poisson distribution and can be randomly selected but weighted by their total reaction rate. Due to a small computational effort, kMC methods can simulate systems of mesoscopic sizes for macroscopic time scales. Previous studies with vacancy diffusion as an alloy mixer have demonstrated that kMC simulations could describe structural properties and thermal ageing of alloys and nanoparticles ${ }^{45,46,50-53}$.

In a previous study ${ }^{53}$, we have considered the vacancy assisted diffusion on singleatom surface alloys for the systems $\mathrm{PtRu} / \mathrm{Ru}(0001), \mathrm{AgPd} / \mathrm{Pd}(111), \mathrm{PtAu} / \mathrm{Au}(111)$ and $\mathrm{InCu} / \mathrm{Cu}(100)$. There we found for example that the diffusion of the foreign atom in $\mathrm{PtRu} / \mathrm{Ru}(0001)$ and $\mathrm{AgPd} / \mathrm{Pd}(111)$ is principally rather similar, only that the diffusion is slower for $\mathrm{Ag}$ in $\mathrm{AgPd} / \mathrm{Pd}(111)$ than for $\mathrm{Pt}$ in $\mathrm{PtRu} / \mathrm{Ru}(0001)$ due to the higher vacancy diffusion barrier. We have now extended this study for these two systems to address a larger mixing ratio of the components of a surface alloy. We will address the stability of the $\mathrm{PtRu} / \mathrm{Ru}(0001)$ and $\mathrm{AgPd} / \mathrm{Pd}(111)$ surface alloy catalysts at operating conditions using 
first-principles-based kMC simulations. The model alloy catalysts have been used, e.g. to study oxygen reduction reaction (ORR $)^{54-57}$. The structural changes in the alloy layers are mediated via vacancy diffusion, with the barriers determined by the DFT calculations.

Experimentally, surface alloys are typically prepared at high annealing temperatures, but their structures are analyzed by scanning tunneling microscopy (STM) at room temperature ${ }^{40,58-60}$. The short-range order (SRO) of the alloys can be quantified by Warren-Cowley coefficients (WCC), which correspond to a parameter to evaluate the randomness of an atom distribution ${ }^{61,62}$. In the analysis of the WCCs derived from the measured STM images taken at room temperature, typically it is assumed that the observed configuration corresponds to the equilibrium structure at the high annealing temperatures ${ }^{58,60}$ which becomes frozen in at lower temperatures because of the immobility of the surface atoms at lower temperatures. We will determine the short-range order from the kMC simulations at different temperatures ranging from the annealing to the room temperature. Thus we will check whether the assumption that the surface alloy structures are frozen in the configuration at the annealing temperature is justified. Furthermore, the corresponding surface energy changes will be monitored with a lattice gas Hamiltonian method. In addition, we will discuss the active site distribution by identifying matching configurations for adsorption of reactive species along the trajectories.

\section{NUMERICAL SETUP}

Total energies were evaluated by periodic DFT calculations within the generalized gradient approximation (GGA) using the software package vASP ${ }^{63}$. The electronic cores were described by the projector augmented wave method ${ }^{4}$, and the exchange-correlation energies were evaluated as suggested by Hammer and Nørskov, namely by using a revised version of the Perdew-Burke-Ernzerhof (RPBE) functional ${ }^{65}$. The wave functions were expanded with a cutoff energy up to $500 \mathrm{eV}$, and the first Brillouin zone was integrated over a $9 \times 9 \times 1$ k-point grid. The activation barriers of vacancy diffusion to a neighboring hexagonal site were derived by DFT calculations following the transition state theory (TST) ${ }^{42}$.

We assume that local atomic configurations determine the surface energies and diffusion barriers to describe the stability of alloy surfaces and vacancy-mediated structure changes. Then, the energies derived from the DFT calculations with a relatively small unit cell can 
be transferred to LGH and kMC calculations for a large system. In order to calculate the parameters for the LGH and kMC using DFT, the alloy surfaces were modeled by a slab consisting of five atomic layers. The $(6 \times 6)$ and $(5 \times 5)$ surface unit cells were used for $\mathrm{PtRu} / \mathrm{Ru}(0001)$ and $\mathrm{AgPd} / \mathrm{Pd}(111)$ surface alloys, respectively. The top three layers of the slabs were fully relaxed, while the bottom two layers were fixed at their bulk positions. A vacuum of $15 \AA$ separated the slabs to avoid any interaction between the periodic images.

For the calculation of adsorption energies of $\mathrm{CO}$ and $\mathrm{OH}$, the semi-empirical $\mathrm{D} 3$ dispersion correction scheme of Grimme with a zero-damping ${ }^{66-68}$ function was employed to include the dispersion effects between adsorbates and metal surfaces ${ }^{69-71}$. The combination of RPBE with D3/zero is known to predict properties of small adsorbates/metal interfaces

reliably ${ }^{69,70,72,73}$. The cutoff radius for the pair interactions was set to $10 \AA$. Note that the screening of vdW interactions in bulk metals is not well-represented in dispersion-correction schemes based on summing up interatomic van der Waals terms ${ }^{69,74}$. Therefore, the vdW interactions in metals and the adsorbate-metal interactions starting from the second surface layer were excluded.

The first-principles-based kinetic Monte Carlo simulations were performed by the general lattice kinetic Monte Carlo (kMC) framework of $\mathrm{kmos}^{75}$. For the kMC simulations, a periodic setup with $21 \times 21$ unit cells was used. At each $\mathrm{kMC}$ step, the reaction table for vacancy diffusion was updated according to the alloy distribution in the six neighboring sites. The pre-exponential factor used in the kMC simulations was set to $10^{13} / \mathrm{s}$. For a further detailed description of the kMC algorithm, we refer to our previous work ${ }^{49}$.

\section{PARAMETRIZATION OF LATTICE GAS HAMILTONIAN AND KINETIC MONTE CARLO}

The stability of $\mathrm{PtRu} / \mathrm{Ru}(0001)$ and $\mathrm{AgPd} / \mathrm{P}(111)$ random surface alloys is derived from their surface energies $E_{S}$ calculated by an LGH method. The basic idea of this approach is that the surface energy is decomposable into local interactions between neighboring atoms and the local atomic configuration. In the case of $n$ distinguishable local configurations, the surface energy is given by

$$
E_{S}=\sum_{i=1}^{n} \frac{E_{i}^{\text {site }} R_{i}}{A}
$$


with site energies $E_{i}^{\text {site }}$ of each configuration $i$, the number of configuration $i$ in the simulation cell $R_{i}$, and the cell area $A$. In our study we have considered 26 local configurations with rotational symmetry $(n=26)$, as shown in Fig. 1, in order to derive the parameters entering the lattice gas Hamiltonian.

We have approximated the site energy of each local configuration by

$$
E_{i}^{\text {site }}=\frac{1}{2} \sum_{j}^{<n n>} \epsilon_{i-j}+\frac{1}{6} \sum_{j, k}^{<n n>} \epsilon_{i-j-k}+\cdots=\frac{1}{2} \sum_{j}^{<n n>} \epsilon_{i-j}+\epsilon_{i-n n}
$$

with decomposed pair $\epsilon_{i-j}$ and pattern $\epsilon_{i-n n}$ energy components, where the sums only included nearest-neighbor (nn) pairs. The double sums leading to the pattern energies $\epsilon_{i-n n}$ have been derived from 26 different alloy configurations illustrated in Fig. 1. To identify the $\epsilon$ values, we performed DFT calculations of this 26 local configurations (see Fig. 1) in $6 \times 6$ and $5 \times 5$ unit cells. The DFT surface energy $E^{\text {alloy }}$ of each configuration is given by

$$
E_{S}^{\text {alloy }}=\frac{1}{A}\left(E_{\text {slab }}^{\text {alloy }}-x E_{\text {bulk }}^{\text {host }}-y E_{\text {bulk }}^{\text {guest }}\right)-E_{S}^{\text {host }}
$$

where $E_{\text {slab }}^{\text {alloy }}$ denotes the total energy of the slab, $A$ is the surface area, $E_{S}^{\text {host }}$ represents the surface energy of the unrelaxed bottom side. $E_{\text {bulk }}^{\text {host }}$ and $E_{\text {bulk }}^{\text {guest }}$ are the bulk energies of host and guest elements, respectively. By linearly decomposing the DFT surface energy, e.g. $E_{S}^{\text {alloy }}=E_{S}$, for 26 considered configurations, the $\epsilon$ values are determined as listed in Tables I and II for PtRu/Ru and $\mathrm{AgPd} / \mathrm{Pd}$ surface alloys, respectively. We limited the sums in Eq. 2 to nearest-neighbor pairs because only these pairs entered the encoding of the diffusion barrier heights. Thus the input for the $\mathrm{kMC}$ simulations and the lattice gas Hamiltonian are consistent. Note that the pair energies $\epsilon_{\mathrm{Pt}-\mathrm{Pt}}$ and $\epsilon_{\mathrm{Ag}-\mathrm{Ag}}$ are evaluated from a full monolayer of $\mathrm{Pt}$ and $\mathrm{Ag}$ on the host substrates, respectively.

The pair energies $\epsilon_{i-j}$ and site corrections $\epsilon_{i-N N}$ are listed for $\mathrm{PtRu} / \mathrm{Ru}(0001)$ and $\mathrm{AgPd} / \mathrm{Pd}(111)$ in Tables I and II, respectively. As far as the pair energies $\epsilon_{i-j}$ are concerned, the expected trend is observed. The interaction energies with respect to the more reactive host, $\mathrm{Ru}$ and $\mathrm{Pd}$, respectively, are larger than those with respect to the less reactive foreign metal, Pt and Ag, respectively. Note that the pattern energies $\epsilon_{i-n n}$ refer to the clean host, single guest atom, and a monolayer of the guest atom, respectively. The fact that there are several negative pattern energies $\epsilon_{i-n n}$ in Tables I and II already indicates that mixed surface alloy states are more stable than phase-separated states, 


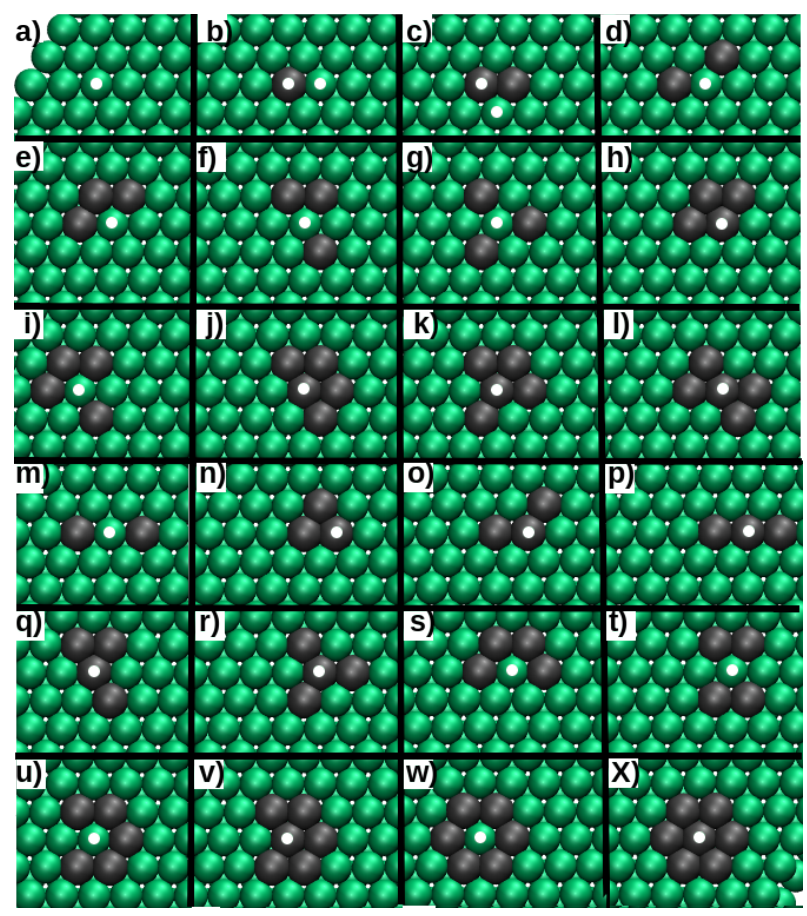

FIG. 1. 24 out of the 26 alloy configurations taken into account to parametrize the lattice gas Hamiltonian. The white dots indicate the central atoms of each site $i$. Please note that $\mathrm{b}$ and $\mathrm{c}$ configurations are used to denote two different sites.

The derived site energies $E_{i}^{\text {site }}$ are used to compute the surface energy of random surface alloys along $\mathrm{kMC}$ trajectories with a customized python code that identifies the site pattern from the local alloy configurations. It is well-known that an efficient LGH code might take more than $10^{6}$ atoms into account ${ }^{37,76}$. The site energies and the LGH code are validated by 21 further DFT calculations of various guest atom concentrations and distributions. The surface formation energies from DFT and LGH agree within the root mean square deviation (RMSD) of $2.636 \mathrm{meV} /$ Atom (6.01\%/Atom). We observe that the LGH reproduces the DFT values better for a low guest atom concentration, below 0.5 ML.

The time evolution of the structural change in the catalyst layer is derived from kMC simulations. The structural change of flat metal surfaces is typically mediated by vacancy diffusion and thus sensitive to the precise vacancy diffusion barriers $\left(\mathrm{E}_{b}\right)$ depending on the surrounding configurations ${ }^{53}$, we considered vacancy diffusion for all possible neighboring alloy configurations shown in Fig. 1. For the kMC simulations, we have considered 156 diffusion barriers calculated by the NEB method, as listed in Tab. III. Then, in each kMC 
step, the reaction table is instantly updated by the arrangement of the nearest neighboring atoms ${ }^{49,53,77}$. Based on the form of the Arrhenius relation, the relative difference between diffusion barriers becomes smaller with increasing temperature. Consequently, in the limit of very high temperatures the probability of all diffusion steps becomes similar resulting in rather random configurations of the alloy. However, at the temperatures used in catalysis, even subtle differences in the diffusion barriers play a significant role with respect to the resulting structures.

The diffusion barrier height is influenced by the strength and number of broken bonds at the transition state. In addition, strain effects caused by the size difference between moving and host atoms and the particular symmetry of the surface affect the barrier heights. Nevertheless, an analysis of the barrier heights indicates that apparently strain effects are not crucial in the diffusion in the considered surface alloy systems. Still, for the particular systems considered by us, we find that in the case of a vacancy surrounded by one guest atom and five host atoms, the diffusion alongside the guest atom is more hindered than the diffusion of the host atom opposite of the guest atom ${ }^{53}$. When increasing the number of guest atoms in the vicinity of the vacancy, this trend does not change. For example, for two and three guest atoms around the vacancy, the energy barrier for Ru atoms alongside a $\mathrm{Pt}$ atom is $\mathrm{E}_{b}=1.73 \mathrm{eV}$ and $1.74 \mathrm{eV}$, and for opposite $\mathrm{Ru}$ diffusion $\mathrm{E}_{b}=1.64 \mathrm{eV}$ and $1.70 \mathrm{eV}$, respectively.

TABLE I. The pair energies $\epsilon_{i-j}$ and site corrections $\epsilon_{i-N N}$ of the 26 considered configurations displayed in Fig. 1 on $\mathrm{PtRu} / \mathrm{Ru}(0001)$ surface alloy.

\begin{tabular}{|c|c|c|c|c|c|c|c|c|}
\hline Pair & $\epsilon_{i-j}$ & & Pattern & $\epsilon_{i-N N}$ & Pattern & $\epsilon_{i-N N}$ & Pattern & $\epsilon_{i-N N}$ \\
\hline $\mathrm{Pt}-\mathrm{Pt}$ & 0.0571 & c) & Ru-2Pt.0 & $-0.1121 \mathrm{~g})$ & Ru-3Pt.2 & $0.2501 \mathrm{k})$ & Pt-4Pt.1 & -0.2684 \\
\hline a) $\mathrm{Ru}-\mathrm{Ru}$ & 0.1624 & d) & Ru-2Pt.1 & $-0.1930 \mathrm{~h})$ & Pt-3Pt.0 & $0.1044 \quad 1)$ & Pt-4Pt.2 & -0.2337 \\
\hline b) Ru-Pt & 0.1027 & m) & Ru-2Pt.2 & $-0.3760 \mathrm{q})$ & Pt-3Pt.1 & $0.0886 \mathrm{u})$ & $\mathrm{Ru}-5 \mathrm{Pt}$ & 0.7241 \\
\hline \multirow[t]{5}{*}{ b) } & 0.1027 & n) & Pt-2Pt.0 & $0.0513 \mathrm{r})$ & Pt-3Pt.2 & $-0.4100 \mathrm{v})$ & Pt-5Pt & -0.1251 \\
\hline & & o) & Pt-2Pt.1 & $-0.0229 \mathrm{~s})$ & Ru-4Pt.0 & $0.2428 \mathrm{w})$ & $\mathrm{Ru}-6 \mathrm{Pt}$ & 1.0066 \\
\hline & & p) & Pt-2Pt.2 & 0.4477 i) & Ru-4Pt.1 & $0.4719 \mathrm{x})$ & Pt-6Pt & 0.0201 \\
\hline & & e) & Ru-3Pt.0 & $-0.0229 \mathrm{t})$ & Ru-4Pt.2 & 0.4614 & & \\
\hline & & f) & Ru-3Pt.1 & $0.0237 \mathrm{j})$ & Pt-4Pt.0 & 0.1930 & & \\
\hline
\end{tabular}


Note that we only considered the influence of the nearest neighbors in the analysis and encoding of the barrier heights for the $\mathrm{kMC}$ simulations. However, taking the direct impact of first and second nearest neighbors into account would drastically increase the number of necessary NEB calculations to evaluate the barrier heights. A computationally inexpensive workaround is, as we showed in our previous study ${ }^{53}$, to take the influence of the second nearest neighbor shell indirectly into account by distinguishing between forth and back diffusion. The symmetry in the nearest neighbor shell of the vacancy is often lifted when additional guest atoms are introduced. Hence, initial and final states become inequivalent. For example, when the $\mathrm{Pt}$ jump (vicinity position 1) from the $\mathrm{Pt}_{5} \mathrm{Ru}$ configuration is considered, the forward and backward jump barriers are 1.42 and $1.22 \mathrm{eV}$, respectively. However, when the forward jump occurs, one of the configurations among $\mathrm{Pt}_{2} \mathrm{Ru}_{4}, \mathrm{Pt}_{3} \mathrm{Ru}_{3}, \mathrm{Pt}_{2} \mathrm{RuPtRu}_{2}$, $\mathrm{Pt}_{4} \mathrm{Ru}_{2}, \mathrm{Pt}_{3} \mathrm{RuPtRu}_{2}, \mathrm{Pt}_{3} \mathrm{RuPt}_{2} \mathrm{Ru}, \mathrm{Pt}_{5} \mathrm{Ru}$, and $\mathrm{Pt}_{6}$ will be adopted depending on the $\mathrm{Pt}$ distribution.

\section{STRUCTURES AND ENERGETICS OF RANDOM SURFACE ALLOYS}

Experimentally, the random surface alloys are typically created by a flash-cool down after deposition of guest atoms with a desired concentration on the host material and hightemperature annealing ${ }^{58,60}$. To numerically determine to structure of surface alloys, we

TABLE II. The pair energies $\epsilon_{i-j}$ and site corrections $\epsilon_{i-N N}$ of the 26 considered configurations displayed in Fig. 1 on $\mathrm{AgPd} / \mathrm{Pd}(111)$ surface alloy.

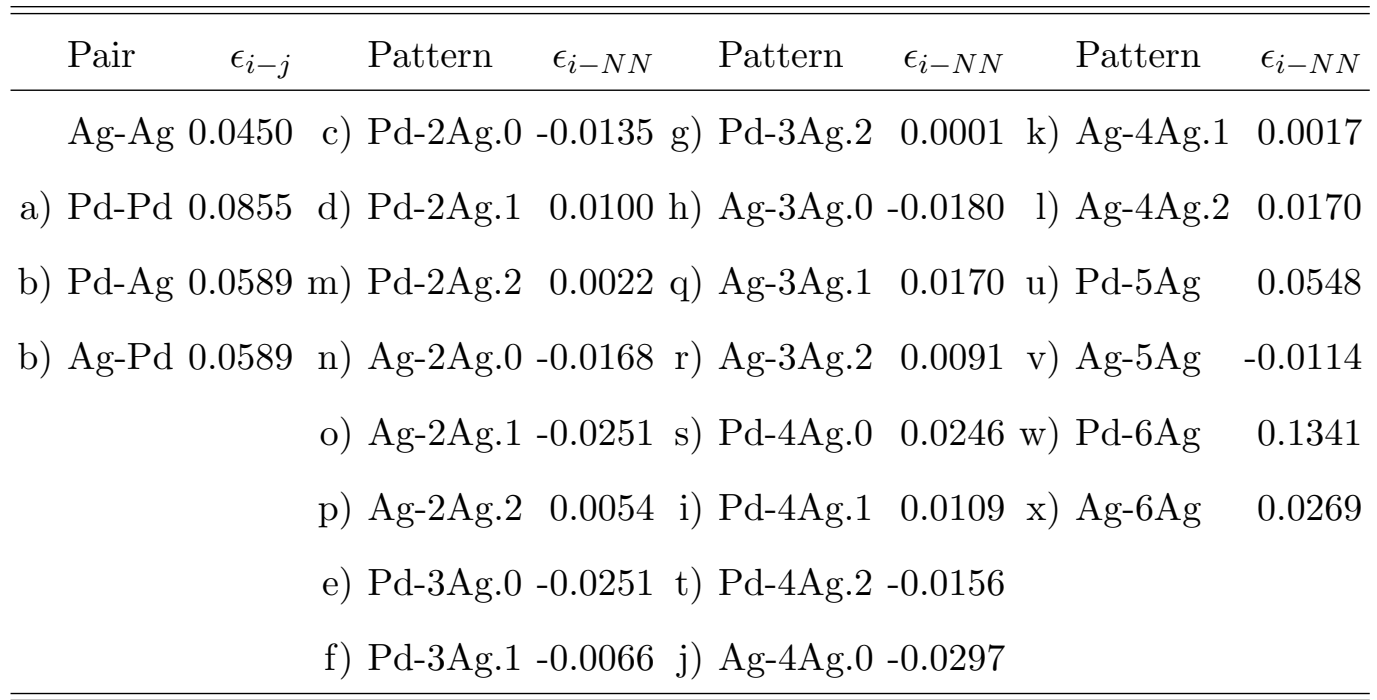


TABLE III. Diffusion barriers $\left(\mathrm{E}_{b}\right)$ of a jump between a nearest neighbor site atom $i$ and the vacancy with the nearest neighbor $(\mathrm{NN})$ configuration $\prod_{i=1}^{6} \operatorname{Atom}_{i}$.

\begin{tabular}{|c|c|c|c|c|c|c|c|c|c|c|c|}
\hline \multicolumn{6}{|c|}{ NN configuration } & \multicolumn{6}{|c|}{ Barriers in back/forth jumps $(\mathrm{eV})$} \\
\hline 1 & 2 & 3 & 4 & 5 & 6 & site1 & site2 & site3 & site 4 & site5 & site6 \\
\hline
\end{tabular}

a) $\mathrm{Ru} \mathrm{Ru} \mathrm{Ru} \mathrm{Ru} \mathrm{Ru} \operatorname{Ru} 1.55 / 1.55$ 1.55/1.55 1.55/1.55 1.55/1.55 1.55/1.55 1.55/1.55

b) Pt Ru Ru Ru Ru Ru 1.37/1.37 1.67/1.67 1.60/1.49 1.63/1.45 1.60/1.49 1.67/1.67

c) Pt Pt Ru Ru Ru Ru 1.40/1.40 1.40/1.40 1.73/1.67 1.64/1.33 1.64/1.33 1.73/1.67

d) Pt Ru Pt Ru Ru Ru 1.37/1.30 1.80/1.80 1.37/1.30 1.72/1.52 1.63/1.40 1.72/1.52

m) Pt Ru Ru Pt Ru Ru 1.39/1.25 1.68/1.57 1.68/1.57 1.39/1.25 1.68/1.57 1.68/1.57

e) Pt Pt Pt Ru Ru Ru 1.40/1.36 1.47/1.47 1.40/1.36 1.74/1.50 1.70/1.33 1.74/1.50

f) $\mathrm{Pt} \mathrm{Pt} \mathrm{Ru} \mathrm{Pt} \mathrm{Ru} \mathrm{Ru} 1.41 / 1.28$ 1.41/1.28 1.79/1.74 1.39/1.23 1.69/1.48 1.69/1.48

g) Pt Ru Pt Ru Pt Ru 1.38/1.24 1.87/1.65 1.38/1.24 1.87/1.65 1.38/1.24 1.87/1.65

s) Pt Pt Pt Pt Ru Ru 1.42/1.26 1.47/1.43 1.47/1.43 1.42/1.26 1.80/1.47 1.80/1.47

i) Pt Pt Pt Ru Pt Ru 1.41/1.30 1.50/1.34 1.41/1.30 1.89/1.64 1.40/1.17 1.89/1.64

1) Pt Pt Ru Pt Pt Ru 1.43/1.24 1.43/1.24 1.84/1.70 1.43/1.24 1.43/1.24 1.84/1.70

u) Pt Pt Pt Pt Pt Ru 1.42/1.22 1.49/1.32 1.47/1.38 1.49/1.32 1.42/1.22 1.90/1.62

w) Pt Pt Pt Pt Pt Pt 1.48/1.30 1.48/1.30 1.48/1.30 1.48/1.30 1.48/1.30 1.48/1.30

a) $\mathrm{Pd} \mathrm{Pd} \mathrm{Pd} \mathrm{Pd} \mathrm{Pd} \mathrm{Pd}$ 0.75/0.75 0.75/0.75 0.75/0.75 0.75/0.75 0.75/0.75 0.75/0.75

b) $\mathrm{Ag} \mathrm{Pd} \mathrm{Pd} \mathrm{Pd} \mathrm{Pd} \mathrm{Pd}$ 0.55/0.55 0.89/0.89 0.75/0.68 0.73/0.68 0.75/0.68 0.89/0.89

c) $\mathrm{Ag} \mathrm{Ag} \mathrm{Pd} \mathrm{Pd} \mathrm{Pd} \mathrm{Pd}$ 0.66/0.66 0.66/0.66 0.89/0.81 0.73/0.58 0.73/0.58 0.89/0.81

d) Ag Pd Ag Pd Pd Pd 0.55/0.49 1.00/1.00 0.55/0.49 0.87/0.79 0.73/0.59 0.87/0.79

m) Ag Pd Pd Ag Pd Pd 0.55/0.49 0.89/0.81 0.89/0.81 0.55/0.49 0.89/0.81 0.89/0.81

e) $\mathrm{Ag} \mathrm{Ag} \mathrm{Ag} \mathrm{Pd} \mathrm{Pd} \mathrm{Pd}$ 0.65/0.60 0.76/0.76 0.65/0.60 0.86/0.72 0.74/0.55 0.86/0.72

f) $\mathrm{Ag} \mathrm{Ag} \mathrm{Pd} \mathrm{Ag} \mathrm{Pd} \mathrm{Pd}$ 0.67/0.60 0.67/0.60 1.01/0.91 0.55/0.42 0.89/0.71 0.89/0.71

g) $\mathrm{Ag} \mathrm{Pd} \mathrm{Ag} \mathrm{Pd} \mathrm{Ag} \mathrm{Pd}$ 0.55/0.42 0.99/0.90 0.55/0.42 0.99/0.90 0.55/0.42 0.99/0.90

s) $\mathrm{Ag} \mathrm{Ag} \mathrm{Ag} \mathrm{Ag} \mathrm{Pd} \mathrm{Pd}$ 0.65/0.53 0.75/0.69 0.75/0.69 0.65/0.53 0.86/0.67 0.86/0.67

i) $\mathrm{Ag} \mathrm{Ag} \mathrm{Ag} \mathrm{Pd} \mathrm{Ag} \mathrm{Pd} 0.66 / 0.53$ 0.75/0.69 0.66/0.53 0.99/0.83 0.56/0.38 1.01/0.85

l) $\mathrm{Ag} \mathrm{Ag} \mathrm{Pd} \mathrm{Ag} \mathrm{Ag} \mathrm{Pd} 0.68 / 0.54$ 0.68/0.54 0.99/0.83 0.68/0.54 0.68/0.54 0.99/0.83

u) $\mathrm{Ag} \mathrm{Ag} \mathrm{Ag} \mathrm{Ag} \mathrm{Ag} \mathrm{Pd}$ 0.66/0.45 0.75/0.62 0.76/0.61 0.75/0.62 0.66/0.45 0.99/0.77

w) $\mathrm{Ag} \mathrm{Ag} \mathrm{Ag} \mathrm{Ag} \mathrm{Ag} \mathrm{Ag} 0.77 / 0.54$ 0.77/0.54 0.77/0.54 0.77/0.54 0.77/0.54 0.77/0.54 

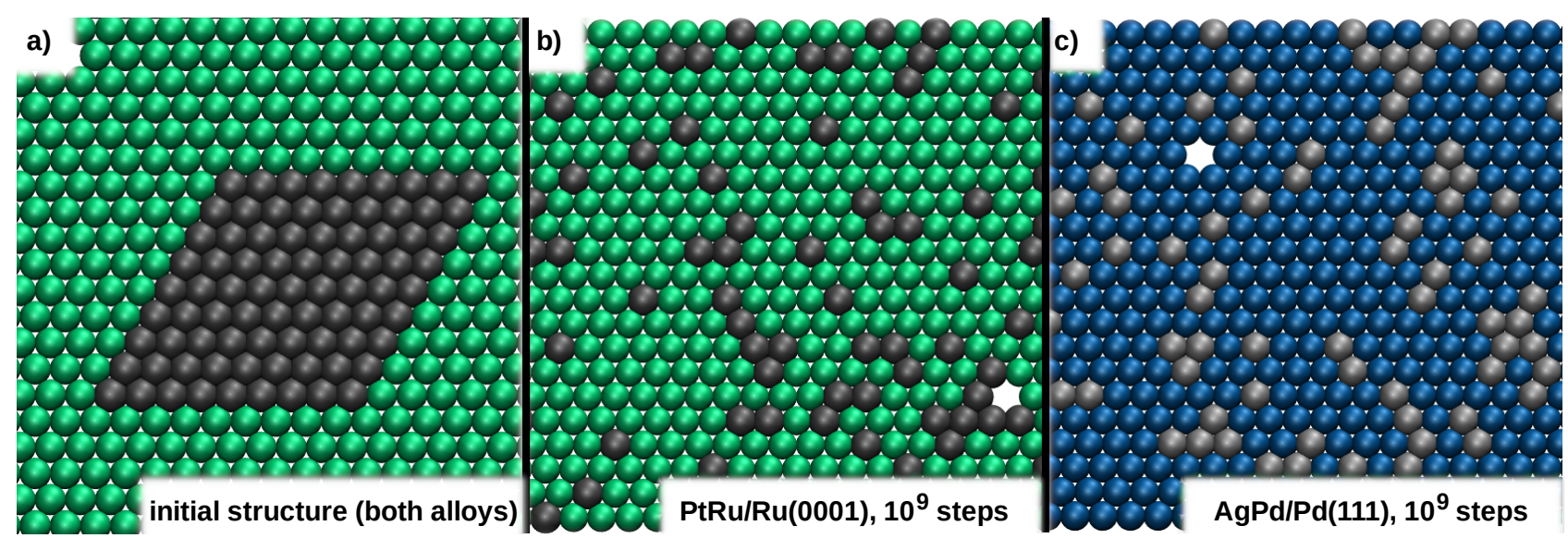

FIG. 2. a) Initial configuration of surface alloys for the kMC simulations and the structures of b) $\operatorname{PtRu}\left(\mathrm{Ru}(0001)\right.$ and c) $\mathrm{AgPd} / \mathrm{Pd}(111)$ after $10^{9} \mathrm{kMC}$ steps at the annealing temperatures of $1350 \mathrm{~K}$ and $800 \mathrm{~K}$, respectively.

performed kMC simulations with a guest atom concentration of $x_{\text {guest }}=0.18$ (80 guest atoms in a $21 \times 21$ simulation cell) at the annealing temperatures of 1350 and $800 \mathrm{~K}$ for $\mathrm{PtRu} / \mathrm{Ru}(0001)$ and $\mathrm{AgPd} / \mathrm{Pd}(111)$ surfaces, respectively. For the initial configuration, the guest atoms are placed in a $9 \times 9$ island area, and the vacancy is placed well outside of the guest atom island as depicted in Fig. 2a.

With this initial configuration, we have performed kMC simulations for the vacancy diffusion in the $\mathrm{PtRu} / \mathrm{Ru}(0001)$ and $\mathrm{AgPd} / \mathrm{Pd}(111)$ surface alloys. The resulting surface alloy structure after $10^{9} \mathrm{kMC}$ steps are shown for the two systems in Figs. $2 \mathrm{~b}$ and c, respectively, where temperatures of $1350 \mathrm{~K}$ and $800 \mathrm{~K}$ for $\mathrm{PtRu} / \mathrm{Ru}(0001)$ and $\mathrm{AgPd} / \mathrm{Pd}(111)$ were assumed, respectively. As there are 441 sites within the $21 \times 21$ unit cell, after $10^{9} \mathrm{kMC}$ steps the vacancy should have visited each atomic site at least $10^{6}$ times on average. The vacancy diffusion acts as a mixer that introduces disorder into the initially ordered structure.

In order to illustrate the evolution of the alloy structures starting with the configuration shown in Fig. 2a, in Fig.3 we have plotted snapshots of the diffusion process after different after $10^{3} \mathrm{kMC}$ steps, $10^{5} \mathrm{kMC}$ steps $10^{7} \mathrm{kMC}$ steps, $10^{9} \mathrm{kMC}$ steps at the annealing temperature of $1350 \mathrm{~K}$ for PtRu/Ru(0001) (Fig.3a-d) and of $800 \mathrm{~K}$ for $\mathrm{AgPd} / \mathrm{Pd}(111)$ (Fig.3e-h). Due to the significantly higher barriers in the PtRu system, the corresponding step numbers are associated with longer elapsed real times, in spite of the higher annealing temperatures compared to the $\mathrm{AgPd}$ system. Comparing the snapshots of the time evolution of 

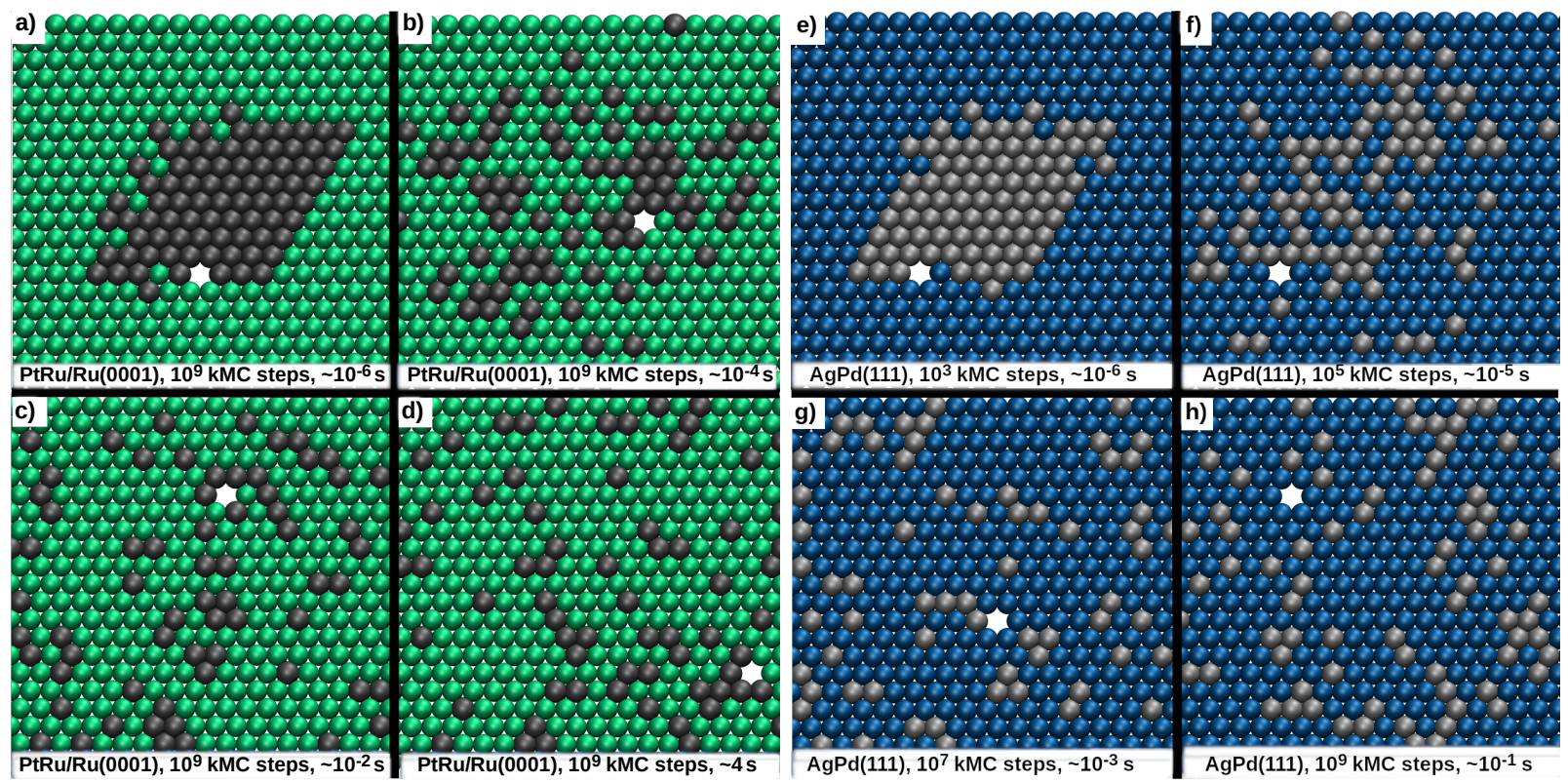

FIG. 3. The distribution of the Pt atoms (a)-d)) and Ag atoms (e)-h))) after $10^{3} \mathrm{kMC}$ steps, $10^{5} \mathrm{kMC}$ steps $10^{7} \mathrm{kMC}$ steps, $10^{9} \mathrm{kMC}$ steps at annealing temperature of $1350 \mathrm{~K}$ and $800 \mathrm{~K}$, respectively. In the panels, the corresponding run times derived from the $\mathrm{kMC}$ algorithm has been given.

the $\mathrm{PtRu} / \mathrm{Ru}(0001)$ and $\mathrm{AgPd} / \mathrm{Pd}(111$ systems, at first glance the evolving structures look rather similar, but there are characteristic differences, as will be discussed in detail below.

The resulting structures are then used as input for further $\mathrm{kMC}$ simulations with stepwise lowered temperatures, using $800 \mathrm{~K}, 400 \mathrm{~K}$ and $298 \mathrm{~K}$ for the $\mathrm{PtRu} / \mathrm{Ru}(0001)$ and $400 \mathrm{~K}$ and $298 \mathrm{~K}$ for the $\mathrm{AgPd} / \mathrm{Pd}(111)$. At each temperature, we perform $10^{9} \mathrm{kMC}$ steps to let the system adjust to the new temperature. After that, we sample the structural properties and surface energies over $10^{8} \mathrm{kMC}$ steps. Note that at the lower temperatures the vacancy jumps become much less frequent. The average time step $(\Delta t)$ on $\mathrm{AgPd} / \mathrm{Pd}(111)$ at room temperature corresponds to $\sim 1.78 \cdot 10^{-4} \mathrm{~s}$ In contrast, on $\mathrm{PtRu} / \mathrm{Ru}(0001)$ the vacancy diffusion barriers are roughly twice as high as on $\mathrm{AgPd} / \mathrm{Pd}(111)$ (see Tab III) making the vacancy jumps much less frequent. Hence the average time for an $\mathrm{kMC}$ step $(\Delta t)$ in the $\mathrm{PtRu} / \mathrm{Ru}(0001)$ system at room temperature corresponds to $\sim 1759.28$ years. This means that practically the surface alloy structures are frozen at room temperature.

For both surface alloys, we determine the randomness of the sampled structures using 

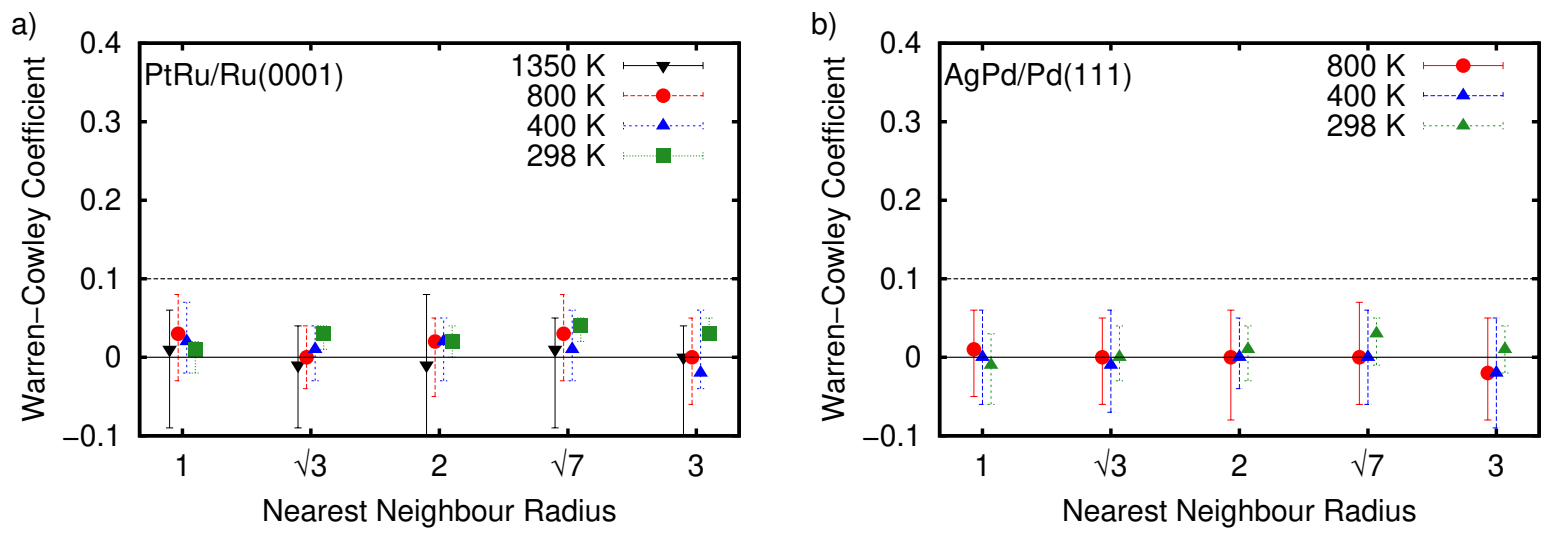

FIG. 4. Warren-Cowley coefficients of $\mathrm{PtRu} / \mathrm{Ru}(0001)$ and $\mathrm{AgPd} / \mathrm{Pd}(111)$ sampled at the $1, \sqrt{3}$, 2, $\sqrt{7}$ and 3 times of the distance to the nearest neighbor at the annealing temperatures of $1350 \mathrm{~K}$ and $800 \mathrm{~K}$.

Warren-Cowley coefficients (WCC). This coefficient represents a measure of the short-range order (SRO) of alloys, which is defined by the probability of finding a type B atom next to a type $\mathrm{A}$ atom $p_{\mathrm{AB}}(r)$ as a function of the distance $r$ and the concentration $x_{\mathrm{B}}$ of type $\mathrm{B}$ atoms, i.e., $\alpha_{\mathrm{AB}}=1-p_{\mathrm{AB}}(r) / x_{\mathrm{B}}$. In general, it is defined between -1 and 1 . Values close to -1 and 1 indicate a high likelihood and unlikelihood, respectively, of the presence of the type $\mathrm{B}$ atom at a $r$. A value of 0 corresponds to a random distribution of type $\mathrm{B}$ atoms. We have sampled the WCCs at every $10^{6} \mathrm{kMC}$ step Figure 4 shows the WCCs averaged over 100 snapshots for all considered temperature. Note first that all WCCs after annealing $(\mathrm{T}=1350 \mathrm{~K}$ for $\mathrm{PtRu} / \mathrm{Ru}(0001)$ and $\mathrm{T}=800 \mathrm{~K}$ for $\mathrm{AgPd} / \mathrm{Pd}(111)$ ) are all very close to 0 , indicating randomly distributed guest atoms in the surface alloys. This is in good agreement with the WCCs derived from STM images taken for these two systems ${ }^{58,60}$ which have in fact been found to be close to zero for a broad variety of metal mixing ratios.

In addition, Fig. 4 also displays the averaged WCCs sampled at the lower temperatures considered in the kMC simulations. The WCC values remain within the range of -0.1 to 0.1 for all simulated temperatures, and no trend as a function of temperatures can be derived within the uncertainty of the averaged values. Note that upon changing the temperature, the frequencies of jumps with different barrier heights changes relative to each other. At very high temperatures, the probabilities of all processes become more and more similar whereas at very low temperatures the process with the lowest barrier becomes dominating. The 

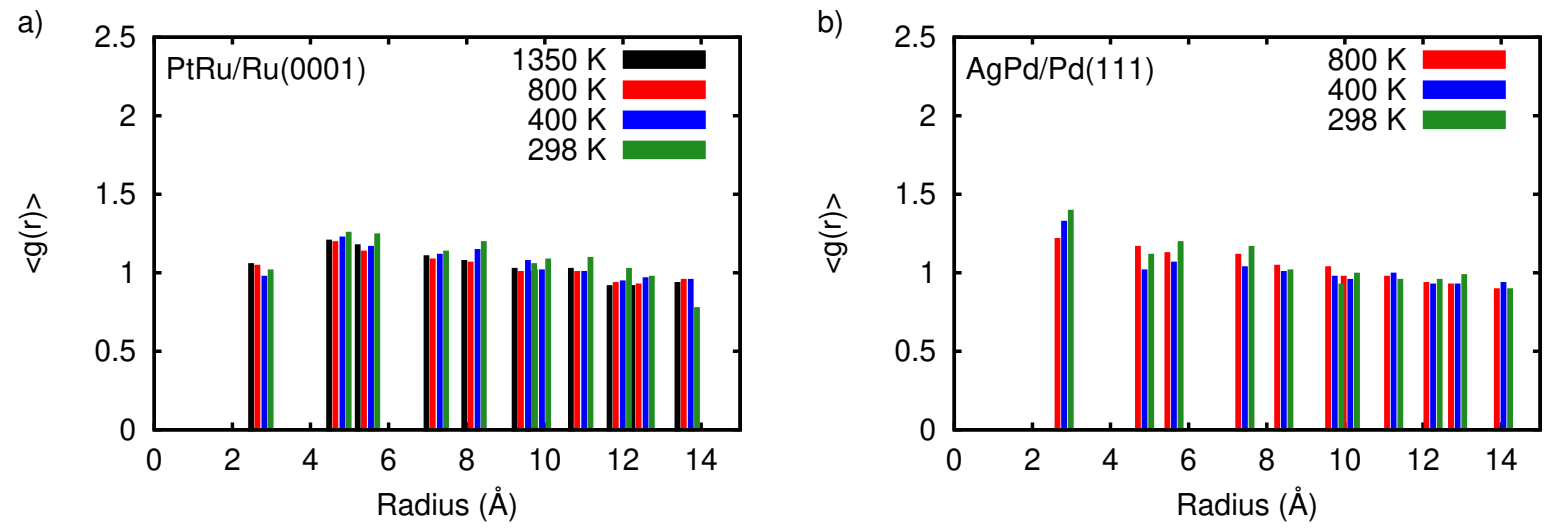

FIG. 5. Pair distribution function $g(r)_{\mathrm{Pt}-\mathrm{Pt}}$ and $g(r)_{\mathrm{Ag}-\mathrm{Ag}}$ at various simulation temperatures averaged over 100 snapshots.

fact that after $10^{9} \mathrm{kMC}$ steps the short-range order at all consider temperatures is close to be entirely random indicates that in the surface alloys $\mathrm{PtRu} / \mathrm{Ru}(0001)$ and $\mathrm{AgPd} / \mathrm{Pd}(111)$ kinetic effects do not play an important role in the structure formation in the long-time limit. Furthermore, it also indicates that in the interpretation of the experimental measured distributions ${ }^{58,60}$ it is well-justified to assume that the prepared surface alloys correspond to equilibrium structures.

Besides using Warren-Cowley coefficients to analyze the short-range order in the surface alloys, we also employed the concept of the pair distribution function (PDF) $g(r)$ to analyze the surface structures. In ideal crystalline materials, $g(r)$ has non-zero values only at lattice sites. Thus the distribution of non-zero values depends on the crystal symmetry and the lattice constant, and the height of the peaks determines the density of atoms at a particular distance $r$. The pair distribution function $g(r)$ represents the local density relative to the bulk density. Thus a value of $g(r)$ larger than one indicates a higher-order at the distance and vice versa for a value smaller than one. Asymptotically, $g(r)$ becomes one in the limit of large distances.

Figure 5 shows the sampled $g(r)_{\mathrm{Pt}-\mathrm{Pt}}$ and $g(r)_{\mathrm{Ag}-\mathrm{Ag}}$ atoms at all considered simulation temperatures. The non-zero values of the sampled $g(r)$ correspond to the sites of the hexagonal surface lattice at distances, the first three peaks are located at $1, \sqrt{3}$, and 2 times the nearest-neighbor distance. First of all, there is again a rather weak temperature dependence of the structural parameters within the statistical uncertainty of the results, confirming 
the results derived from the Warren-Cowley coefficients. Still there are some differences from a purely disordered structure and also some characteristic differences between the $\mathrm{PtRu} / \mathrm{Ru}(0001)$ and the $\mathrm{AgPd} / \mathrm{Pd}(111)$ surface alloys. Overall, for both systems we observe a slight decrease of the RDF from values larger than one to the expected value of one at large distances. However, whereas $\mathrm{AgPd} / \mathrm{Pd}(111)$ exhibits the $\mathrm{PDF}$ maximum for nearest neighbors, the PDF of $\mathrm{PtRu} / \mathrm{Ru}(0001)$ is maximal for second- and third nearest neighbors. This indicates a slightly higher tendency for the clustering of Ag atoms in the AgPd surface alloys compared to the $\mathrm{Pt}$ atoms in the PtRu atoms.

Now both considered surface alloys are in principle rather similar. The larger element alloyed into the surface is also the less reactive one with the smaller cohesive energy. However, whereas the lattice mismatch between $\mathrm{Ru}(0001)$ and $\mathrm{Pt}(111)$ is about $2.5 \%$, it is almost $5 \%$ between $\mathrm{Ag}(111)$ and $\mathrm{Pd}(111)$, so the $\mathrm{Ag}$ atoms experience a larger compressive lattice strain. This might be the reason that the barrier for vacancy diffusion in a pure Pt environment is smaller than in a pure $\mathrm{Ru}$ environment on $\mathrm{Ru}(0001)$, whereas it is larger in a pure Ag environment than in a pure $\mathrm{Pd}$ environment on $\mathrm{Pd}(111)$ (see Tab. III). Furthermore, the reduction of the barrier for the backwards jump compared to the barrier for the forward jump is for Pd relatively and also absolutly smaller than for Pt which makes the backward jump more likely for Pd than for Pt. This means that an ensemble of connected Pd atoms in a $\mathrm{PdAg} / \mathrm{Pd}(111)$ surface alloy shows a larger tendency to stay together than an ensemble of connected $\mathrm{Pt}$ atoms in a $\mathrm{PtRu} / \mathrm{Ru}(0001)$ which is reflected by the different posions of the maxima in the PDF shown in Fig. 5.

In Fig. 6, the evolution of the surface energy of the surface alloys along the kMC trajectory are depicted at every $10^{6} \mathrm{kMC}$ steps. First of we compare these energies to the fully phaseseparated states whose energy can be determined by weighting the surface energies of the clean host and and of the host covered by a monolayer of the foreign element. This surface energy is given by $E_{S}=(1-x) E_{S}^{\text {host }}+x E_{S}^{\mathrm{ML} / \text { host }}$ with the concentration of foreign element $x$. For both surface alloys, the surface energy of the phase separated systems amounts to 135.91 and $67.70 \mathrm{meV} / \AA^{2}$ for Pt and Ag, respectively. These surface energies shown in Fig. 6 are all distinctively smaller than these surface energies confirming that the mixed surface alloy configurations are energetically more stable, as already infered when discussing the pair energies listed in Tables I and II.

We observe that the energies are slightly getting lowered along the trajectories upon de- 

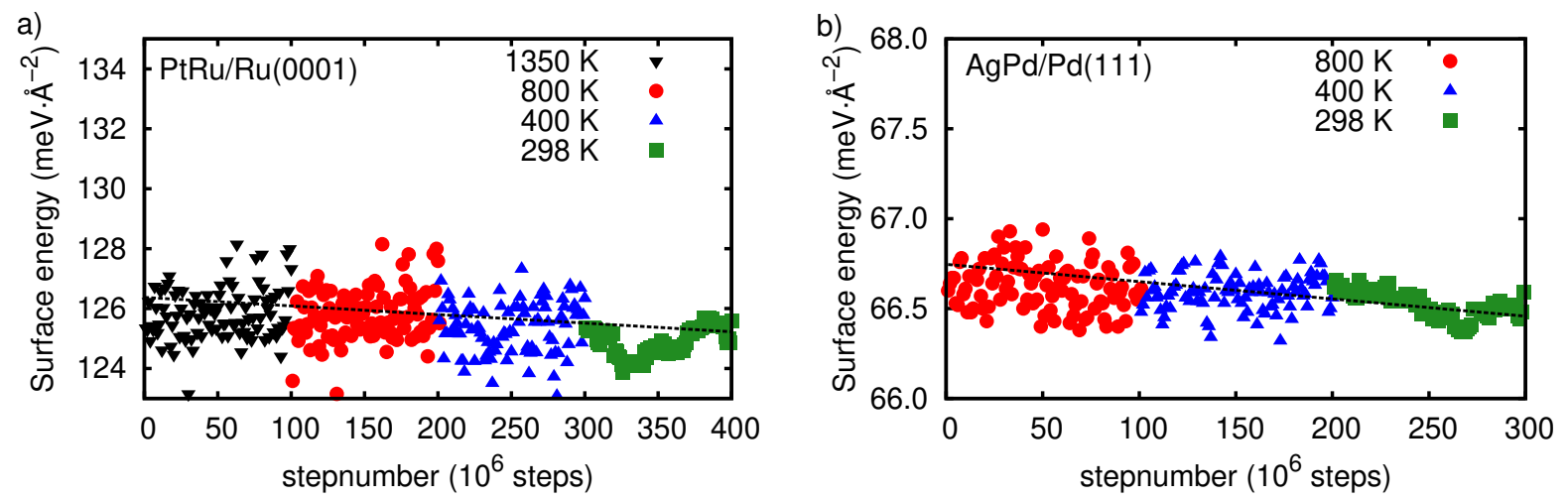

FIG. 6. Evolution of the surface energy along the kMC trajectory on $\mathrm{PtRu} / \mathrm{Ru}(0001)$ and $\mathrm{Ag} / \mathrm{Pd} / \mathrm{Pd}(111)$. The $10^{8} \mathrm{kMC}$ steps correspond to $5.55 \cdot 10^{18} \mathrm{~s}(298 \mathrm{~K}), 2.23 \cdot 10^{12} \mathrm{~s}(400 \mathrm{~K})$, $1.89 \cdot 10^{3} \mathrm{~s}(800 \mathrm{~K})$, and $5.45 \cdot 10^{-1} \mathrm{~s}(1350 \mathrm{~K})$ on the $\mathrm{PtRu} / \mathrm{Ru}(0001)$ and to $1.78 \cdot 10^{4} \mathrm{~s}(298 \mathrm{~K})$, $1.18 \cdot 10^{2} \mathrm{~s}(400 \mathrm{~K}), 1.72 \cdot 10^{-2} \mathrm{~s}(800 \mathrm{~K})$ on $\mathrm{Ag} / \mathrm{Pd} / \mathrm{Pd}(111)$.

creasing the temperature. The dashed lines are a guide for the eyes. Along both trajectories, the spreads of surface energies at the annealing temperatures are around 4 and $1 \mathrm{meV}$ on the $\mathrm{PtRu} / \mathrm{Ru}(0001)$ and $\mathrm{AgPd} / \mathrm{Pd}(111)$, respectively. Note that the small change of about $1 \mathrm{meV} / \AA^{2}$ upon lowering the temperature might be misleading. Qualitatively the lowering of the energies of the visited surface configurations for decreasing temperatures is of course expected. Within the $\mathrm{kMC}$ simulations it is due to the fact that configurations associated with higher barriers become less frequently occupied at lower temperatures. Still, the randomness of the structures does not change, as demonstrated by the WCC in Fig. 4 and PDF in Fig. 5. Therefore, the random surface structures created at the annealing temperatures in principle also remain stable at lower temperatures which means that they are representative for all temperatures.

The variation in the surface energies along the trajectors remain approximately constant separately for both systems down to a temperature of $400 \mathrm{~K}$. Interestingly, at room temperature both systems exhibit a reduced spread in the surface energies with a long-time variation. Obviously steps that significantly change the surface energies are already effectively frozen in at this temperature. 

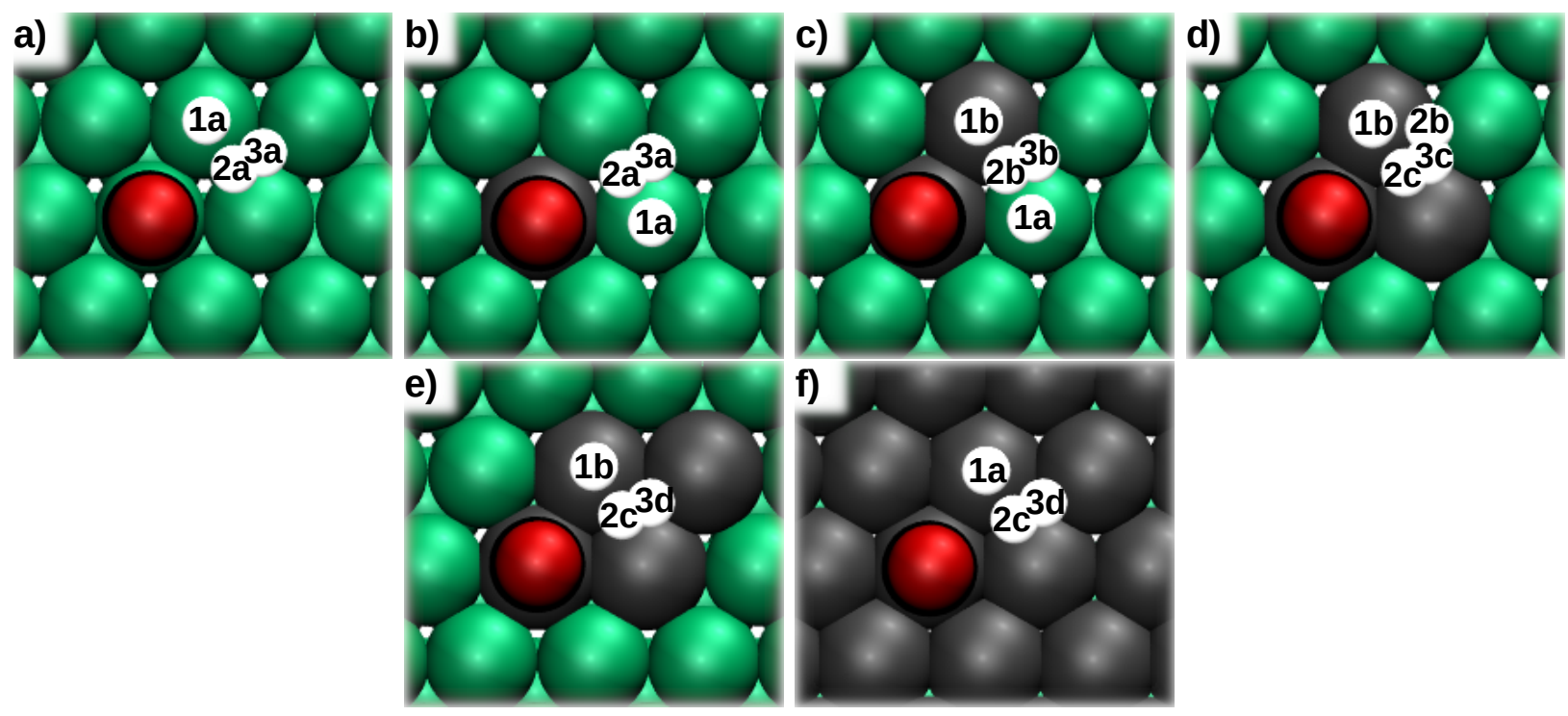

FIG. 7. Configurations of coadsorbed $\mathrm{CO}$ and $\mathrm{OH}$ considered in our study. The $\mathrm{CO}$ molecule that is explicitly included in the panels is typically located at a top position. The adsorbed $\mathrm{OH}$ molecule is not explicitly plotted, the numbers 1, 2 and 3 denote its top, bridge and threefold position, while the letters characterize the different local arrangements of the Pt-Ru ensembles.

\section{ADSORPTION SITE ANALYSIS}

After analyzing and identifying alloy structures and randomness as a function of the temperature, we estimate the catalytic performance of the $\mathrm{PtRu} / \mathrm{Ru}(0001)$ alloy surface for CO electro-oxidation. This analysis is motivated by the experimental work of Klein et al., who analyzed the activity of $\mathrm{PtRu} / \mathrm{Ru}(0001)$ surface alloys by focussing on adsorption ensembles for catalyzing the $\mathrm{CO}_{2}$ formation. In their work, they found the $\mathrm{Pt}_{1} \mathrm{Ru}_{3}$ ensemble to be the most active one. Since calculating the activity by DFT is beyond the scope of this study, we follow the argumentation of Klein et al. and associate the $\mathrm{Pt}_{1} \mathrm{Ru}_{3}$ ensemble with the highest catalytic activity ${ }^{78}$.

For the classification of other adsorption sites, we calculated the energies for the coadsorption of $\mathrm{CO}$ and $\mathrm{OH}$ on PtRu surface alloys. As demonstrated in Fig. 7, we consider surface ensembles of four atoms with different Pt content. The CO molecule typically stays at the top site above a $\mathrm{Pt}$ atom where available, whereas the most favorable $\mathrm{OH}$ adsorption site depends on the particular tetrameric ensemble. In Tab. IV the adsorption energies are listed for $\mathrm{OH}$ adsorption on the threefold, bridge and top sites. Please note that in the case 
of various adsorption sites with the same coordination, only the most stable one is considered. For example, as far as the structure shown in Fig. 7c is concerned, OH can adsorb on the top site of either $\mathrm{Ru}$ or $\mathrm{Pt}$, and in Fig. 7d two different $\mathrm{OH}$ bridge sites are present. In turns out that in both cases, the site that includes bonding to $\mathrm{Ru}$ is more stable.

According to the Sabatier principle, a catalytically active sites needs to exhibit the "right" adsorption energy, neither too strong nor too weak, so that this site can promote a reaction but does not bind the products too strongly so that they can still desorb from this site ${ }^{79}$. Taking just the maximum adsorption energy of an ensemble as the activity criterion and assuming that the $\mathrm{Pt}_{1} \mathrm{Ru}_{3}$ ensemble corresponds to an active configuration, other active sites need to have adsorption energies close to the one of the $\mathrm{Pt}_{1} \mathrm{Ru}_{3}$ ensemble which amounts to $-1.69 \mathrm{eV}$. According to Tab. IV, the maximum adsorption energy closest to the one of the $\mathrm{Pt}_{3} \mathrm{Ru}_{1}$ ensemble is associated with the $\mathrm{Pt}_{3} \mathrm{Ru}_{1}$ ensemble where we find an adsorption energy of $-1.43 \mathrm{eV}$. The relative large differenc of $0.26 \mathrm{eV}$ suggests that indeed the $\mathrm{Pt}_{1} \mathrm{Ru}_{3}$ ensemble is the one with the highest catalytic activity for CO electro-oxidation.

The catalytic activity of a particular $\mathrm{PtRu} / \mathrm{Ru}(0001)$ surface alloy should then be given by the abundance of the most active configuration. Fig. 8 shows the mean number of sampled number of $\mathrm{Pt}_{4-x} \mathrm{Ru}_{x}$ per area as a function of the temperature. At the $\mathrm{Pt}$ concentration of $x_{\mathrm{Pt}}=0.18$ considered in this study, the $\mathrm{Pt}_{1} \mathrm{Ru}_{3}$ and $\mathrm{Pt}_{2} \mathrm{Ru}_{2}$ ensembles are the most abundant at all temperatures, and there abundance increases upon lowering the temperature at the

TABLE IV. The adsorption energies in $\mathrm{eV}$ of $\mathrm{CO}$ and $\mathrm{OH}$ coadsorption on different $\mathrm{Pt}-\mathrm{Ru}$ tetrameric ensembles of the $\mathrm{PtRu} / \mathrm{Ru}(0001)$ surface alloys for the $\mathrm{CO}$ molecule at a $\mathrm{Pt}$ top site, where available, and the $\mathrm{OH}$ molecules at the most favorable threefold, bridge and top site, respectively.

\begin{tabular}{lrrr}
\hline \hline $\mathrm{OH}$ site & \multicolumn{2}{c}{ threefold bridge } & top site \\
\hline $\mathrm{Pt}_{0} \mathrm{Ru}_{4}$ & -2.03 & -1.80 & -1.75 \\
$\mathrm{Pt}_{1} \mathrm{Ru}_{3}$ & -1.65 & -1.69 & -1.46 \\
$\mathrm{Pt}_{2} \mathrm{Ru}_{2}$ & -1.16 & -1.10 & -1.34 \\
$\mathrm{Pt}_{3} \mathrm{Ru}_{1}$ & -1.22 & -0.19 & -1.43 \\
$\mathrm{Pt}_{4} \mathrm{Ru}_{0}$ & -0.24 & -0.40 & -0.25 \\
$\mathrm{Pt} \mathrm{Ru}(0001)$ & 0.14 & -0.22 & -0.42 \\
\hline \hline
\end{tabular}




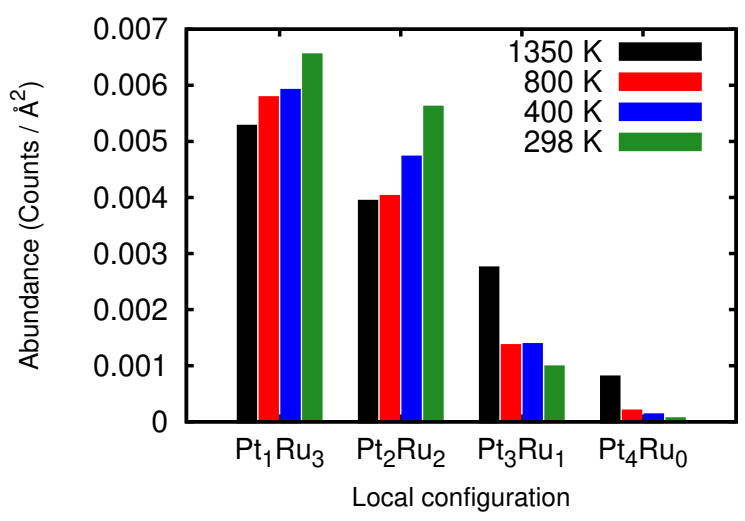

FIG. 8. Abundance of sampled local alloy ensembles (Counts $\left./ \AA^{2}\right)$ at various temperatures.

expense of the $\mathrm{Pt}_{3} \mathrm{Ru}_{1}$ and $\mathrm{Pt}_{4} \mathrm{Ru}_{0}$ ensembles. Hence this low $\mathrm{Pt}$ concentration is indeed favorable for a high concentration of catalytically active sites.

Finally we like to note that in spite of the high stability of the $\mathrm{PtRu} / \mathrm{Ru}(0001)$ alloy found in our kMC study, in cyclic voltammogram experiments, Klein et al. found a rapid loss of catalytic activity for potentials higher than $0.90 \mathrm{~V}^{78}$. Additionally, Engstfeld et al. identified a surface reconstruction of Pt-modified $\mathrm{Ru}(0001)$ electrodes at potentials above $0.90 \mathrm{~V}^{80,81}$, resulting in 3D cluster formation with increasing clean $\mathrm{Ru}$ areas at $\mathrm{Pt}$ concentrations lower than 0.29 . However, as these changes are induced by changes in the electrode potential, their description would require a grand-canonical approach taking the electrochemical environment into account ${ }^{82,83}$, but they are not captured by our kMC simulations.

\section{CONCLUSION}

We have performed DFT-based kMC simulations for $\mathrm{PtRu} / \mathrm{Ru}(0001)$ and $\mathrm{AgPd} / \mathrm{Pd}(111)$ in order to address the formation and stability of surface alloy formation at various temperatures between annealing and room temperature based on vacancy-mediated diffusion mechanisms. By combining the activation barriers from DFT calculations and kMC simulations, we analyze the kinetic stability of the random surface alloys. After annealing, the alloy structures show a high degree of randomness comparable to the experimental results measured by STM images, as shown by the small Warren-Cowley coefficients derived from the $\mathrm{kMC}$ structures which indicate a vanishing short-range order. We find a minor temper- 
ature dependence of the resulting structures. However, at room temperature the vacancy diffusion events are so rare, in particular for the $\mathrm{PtRu} / \mathrm{Ru}(0001)$ system due to their large diffusion barriers, that the alloy structures can be considered to be frozen on the time scale typically used in experiments.

Furthermore, we analysed the abundance of local $\mathrm{Pt}_{4-x} \mathrm{Ru}_{x}$ ensembles which are supposed to be relevant for the electrocatalytic activity of $\mathrm{PtRu} / \mathrm{Ru}(0001)$ with respect to $\mathrm{CO}$ oxidation. On average, $\mathrm{Pt}_{1} \mathrm{Ru}_{3}$ and $\mathrm{Pt}_{2} \mathrm{Ru}_{2}$ configurations are most abundant over the whole considered temperature range. Especially the $\mathrm{Pt}_{1} \mathrm{Ru}_{3}$ ensemble which is supposed to be particularly active shows the highest abundance at the studied Pt concentration of 0.18.

\section{ACKNOWLEDGEMENT}

This research has been supported by the German Research Foundation (DFG) through contracts GR 1503/30-1 and GR 1503/39-1. Support by the Dr. Barbara Mez-Starck Foundation and computer time provided by the bwHPC initiative and the bwHPC-C5 project funded by the Baden-Württemberg government (MWK) and the German Research Foundation (DFG) through grant number INST 40/575-1 FUGG (JUSTUS 2 cluster) are gratefully acknowledged. This work contributes to the research performed at CELEST (Center for Electrochemical Energy Storage Ulm-Karlsruhe).

* david.mahlberg@uni-ulm.de

$\dagger$ sung.sakong@uni-ulm.de

$\ddagger$ axel.gross@uni-ulm.de

1 L. Liu and A. Corma, Chem. Rev. 118, 4981 (2018).

2 Y. Gohda, S. Schnur, and A. Groß, Faraday Discuss. 140, 233 (2008).

3 W. Yu, M. D. Porosoff, and J. G. Chen, Chem. Rev. 112, 5780 (2012).

4 A. Groß, J. Phys.: Condens. Matter 21, 084205 (2009).

5 G. Kyriakou, M. B. Boucher, A. D. Jewell, E. A. Lewis, T. J. Lawton, A. E. Baber, H. L. Tierney, M. Flytzani-Stephanopoulos, and E. C. H. Sykes, Science 335, 1209 (2012).

6 J. Greeley, Annu. Rev. Chem. Biomol. Eng. 7, 605 (2016). 
7 H. Li, K. Shin, and G. Henkelman, J. Chem. phys. 149, 174705 (2018).

8 M. T. Darby, R. Réocreux, E. C. H. Sykes, A. Michaelides, and M. Stamatakis, ACS Catalysis 8, 5038 (2018).

9 H. Li, W. Chai, and G. Henkelman, J. Mater. Chem. A Mater. Energy Sustain. 7, 23868 (2019).

10 R. Schlögl, Angew. Chem. In. Ed. 37, 2333 (1998).

11 Y. Okamoto, Chem. Phys. Lett. 395, 279 (2004).

12 M. Andersen, J. S. Cingolani, and K. Reuter, J. Phys. Chem. C 123, 22299 (2019).

13 A. H. Motagamwala and J. A. Dumesic, Chem. Rev. (2020).

14 T. A. A. Batchelor, J. K. Pedersen, S. H. Winther, I. E. Castelli, K. W. Jacobsen, and J. Rossmeisl, Joule 3, 834 (2019).

15 J. K. Pedersen, T. A. A. Batchelor, A. Bagger, and J. Rossmeisl, ACS Catal. 10, 2169 (2020).

16 R. Ferrando, J. Jellinek, and R. L. Johnston, Chem. Rev. 108, 845 (2008).

17 P. Strasser, S. Koh, T. Anniyev, J. Greeley, K. More, C. Yu, Z. Liu, S. Kaya, D. Nordlund, H. Ogasawara, et al., Nat. Chem. 2, 454 (2010).

18 S. Sakong, D. Mahlberg, T. Roman, M. Li, M. Pandey, and A. Groß, J. Phys. Chem. C, J. Phys. Chem. C 124, 27604 (2020).

19 A. Schlapka, M. Lischka, A. Groß, U. Käsberger, and P. Jakob, Phys. Rev. Lett. 91, 016101 (2003).

20 M. Lischka, C. Mosch, and A. Groß, Electrochim. Acta 52, 2219 (2007).

21 Y. Gohda and A. Groß, J. Electroanal. Chem. 607, 47 (2007).

22 O. Inderwildi, S. Jenkins, and D. King, Surf. Sci. 601, L103 (2007).

23 S. Sakong, C. Mosch, and A. Groß, Phys. Chem. Chem. Phys. 9, 2216 (2007).

24 J. K. Nørskov, J. Rossmeisl, A. Logadottir, L. Lindqvist, J. R. Kitchin, T. Bligaard, and H. Jonsson, J. Phys. Chem. B 108, 17886 (2004).

25 J. T. Margraf and K. Reuter, ACS Omega 4, 3370 (2019).

26 A. Bruix, J. T. Margraf, M. Andersen, and K. Reuter, Nature Catalysis 2, 659 (2019).

27 P. Liu and J. K. Nørskov, Phys. Chem. Chem. Phys. 3, 3814 (2001).

28 A. Roudgar and A. Groß, J. Electroanal. Chem. 548, 121 (2003).

29 A. Roudgar and A. Groß, Phys. Rev. B 67, 033409 (2003).

30 M. Li, S. Sakong, and A. Groß, ACS Catal. 11, 7411 (2021).

31 M. Kahlich, H. Gasteiger, and R. Behm, J. Catal. 182, 430 (1999). 
32 Y. Denkwitz, B. Schumacher, G. Kučerová, and R. J. Behm, J. Catal. 267, 78 (2009).

33 D. Friebel, D. J. Miller, D. Nordlund, H. Ogasawara, and A. Nilsson, Angew. Chem. Int. Ed. 50, $10190(2011)$.

34 A. M. Abdel-Mageed, B. Rungtaweevoranit, M. Parlinska-Wojtan, X. Pei, O. M. Yaghi, and R. J. Behm, J. Am. Chem. Soc. 141, 5201 (2019).

35 A. Feltz, U. Memmert, and R. Behm, Chem. Phys. Lett. 192, 271 (1992).

36 J. Végh, J. Supercomput. 76, 9430 (2020).

37 D. B. Laks, L. Ferreira, S. Froyen, and A. Zunger, Phys. Rev. B 46, 12587 (1992).

38 S. V. Barabash, V. Blum, S. Müller, and A. Zunger, Phys. Rev. B 74, 035108 (2006).

39 H. Hoster, E. Filonenko, B. Richter, and R. Behm, Phys. Rev. B 73, 165413 (2006).

40 A. Bergbreiter, H. E. Hoster, and R. J. Behm, Chem. Phys. Chem. 12, 1148 (2011).

41 A. Bergbreiter, O. B. Alves, and H. E. Hoster, ChemPhysChem 11, 1505 (2010).

42 P. Hänggi, P. Talkner, and M. Borkovec, Rev. Mod. Phys. 62, 251 (1990).

43 J. Hafner, Journal of computational chemistry 29, 2044 (2008).

44 K. A. Fichthorn and W. H. Weinberg, J. Chem. Phys. 95, 1090 (1991).

45 M. Müller and K. Albe, Beilstein J Nanotechnol 2, 40 (2011).

46 E. Martínez, O. Senninger, C.-C. Fu, and F. Soisson, Phys. Rev. B 86, 224109 (2012).

47 A. Jansen, Phys. Rev. B 69, 035414 (2004).

48 K. Reuter and M. Scheffler, Phys. Rev. B 73, 045433 (2006).

49 C. Sendner, S. Sakong, and A. Groß, Surf. Sci. 600, 3258 (2006).

50 Z. Mao, C. K. Sudbrack, K. E. Yoon, G. Martin, and D. N. Seidman, Nat. Mater. 6, 210 (2007).

51 M. Nastar and F. Soisson, Phys. Rev. B 86, 220102 (2012).

52 P. Zoontjens, G. Grochola, I. Snook, and S. Russo, J. Phys. Condens. Matter 23, 015302 (2010).

53 D. Mahlberg and A. Groß, Chem. Phys. Chem. 2021, 29 (2020).

54 D. A. Slanac, W. G. Hardin, K. P. Johnston, and K. J. Stevenson, Journal of the American Chemical Society 134, 9812 (2012).

55 L. A. Mancera, R. J. Behm, and A. Groß, Phys. Chem. Chem. Phys. 15, 1497 (2013).

56 Y. Ma, T. Diemant, J. Bansmann, and R. Behm, Phys. Chem. Chem. Phys. 13, 10741 (2011).

57 S. Brimaud, A. Engstfeld, O. Alves, H. Hoster, and R. Behm, Top. Catal. 57, 222 (2014).

58 H. Hoster, A. Bergbreiter, P. Erne, T. Hager, H. Rauscher, and R. Behm, Phys. Chem. Chem. Phys. 10, 3812 (2008). 
59 A. K. Engstfeld, S. Beckord, C. D. Lorenz, and R. J. Behm, Chem. Phys. Chem. 13, 3313 (2012).

60 A. K. Engstfeld, H. Hoster, and R. Behm, Phys. Chem. Chem. Phys. 14, 10754 (2012).

61 J. M. Cowley, J. Appl. Phys. 21, 24 (1950).

62 B. Warren, New York (1990).

63 G. Kresse and J. Furthmüller, Phys. Rev. B 54, 11169 (1996).

64 P. E. Blöchl, Phys. Rev. B 50, 17953 (1994).

65 B. Hammer, L. B. Hansen, and J. K. Nørskov, Phys. Rev. B 59, 7413 (1999).

66 S. Grimme, J. Antony, S. Ehrlich, and H. Krieg, J. Chem. Phys. 132, 154104 (2010).

67 S. Grimme, Wiley Interdiscip. Rev. Comput. Mol. Sci. 1, 211 (2011).

68 S. Grimme, A. Hansen, J. G. Brandenburg, and C. Bannwarth, Chem. Rev. 116, 5105 (2016).

69 K. Tonigold and A. Groß, J. Comput. Chem. 33, 695 (2012).

70 K. Forster-Tonigold and A. Groß, J. Chem. Phys. 141, 064501 (2014).

71 B. Koslowski, A. Tschetschetkin, N. Maurer, P. Ziemann, J. Kučera, and A. Groß, J. Phys. Chem. C 117, 20060 (2013).

72 S. Sakong, K. Forster-Tonigold, and A. Groß, J. Chem. Phys. 144, 194701 (2016).

73 D. Mahlberg, S. Sakong, K. Forster-Tonigold, and A. Groß, J. Chem. Theory Comput. 15, $3250(2019)$.

74 G. Mercurio, E. R. McNellis, I. Martin, S. Hagen, F. Leyssner, S. Soubatch, J. Meyer, M. Wolf, P. Tegeder, F. S. Tautz, and K. Reuter, Phys. Rev. Lett. 104, 036102 (2010).

75 M. J. Hoffmann, S. Matera, and K. Reuter, Comput. Phys. Commun. 185, 2138 (2014).

76 S. Müller, J. Phys.: Cond. Matter 15, R1429 (2003).

77 C. Sendner and A. Groß, J. Chem. Phys. 127, 014704 (2007).

78 J. Klein, S. Brimaud, A. Engstfeld, and R. Behm, Electrochim. Acta (2019).

79 P. Sabatier, Ind. Eng. Chem. Res. 18, 1005 (1926).

80 A. K. Engstfeld, S. Brimaud, and R. J. Behm, Angew. Chem. Int. Ed. Engl. 53, 12936 (2014).

81 A. Engstfeld, J. Klein, S. Brimaud, and R. Behm, Surf. Sci. 631, 248 (2015).

82 F. Gossenberger, T. Roman, and A. Groß, Surf. Sci. 631, 17 (2015).

83 A. Groß and S. Sakong, Curr. Opin. Electrochem. 14, 1 (2019). 